\title{
Biomechanical alterations of gait on overweight subjects
}

\author{
Fabiana Rodrigues Silva ${ }^{1}$, Adriane Mara de Souza Muniz ${ }^{2}$, Lucenildo Silva Cerqueira ${ }^{3}$, \\ Jurandir Nadal ${ }^{3 *}$ \\ ${ }^{1}$ Post-graduate Program in Physical Education, Federal University of Rio de Janeiro, Rio de Janeiro, RJ, Brazil. \\ ${ }^{2}$ Army School of Physical Education, Rio de Janeiro, RJ, Brazil. \\ ${ }^{3}$ Biomedical Engineering Program, Alberto Luiz Coimbra Institute for Graduate Studies and Research in Engineering, Federal \\ University of Rio de Janeiro, Rio de Janeiro, RJ, Brazil.
}

\begin{abstract}
Introduction: Obesity is a major global public health issue and approximately half of the population is classified as overweight. Many studies have investigated gait modification in obese people; however, no research has been carried out in overweight subject's gait influence. Methods: The goal of this study was to identify biomechanical changes on gait in overweight subjects by the application of principal component analysis (PCA). Two groups of adults participated of this study: overweight $\left(\mathrm{n}=9 ; 25.0<\right.$ Body Mass Index $\left.<29.9 \mathrm{~kg} / \mathrm{m}^{2}\right)$, and normal-weight $\left(\mathrm{n}=15 ; 20.0<\right.$ Body Mass Index $<24.9 \mathrm{~kg} / \mathrm{m}^{2}$. Three-dimensional kinematics of the lower limb and ground reaction forces (GRF) were recorded during gait. PCA was performed on data. Results: PCA evidenced statistical differences at the first principal component (PC) of the sagittal ankle movement, anteroposterior and mediolateral GRF, as well as at the third PC of the sagittal hip movement and mediolateral GRF. Overweight subjects walked with reduced ankle plantarflexion at toe-off and reduced hip flexion at the heel strike and at mid swing, as well as a reduced hip extension during push off. Additionally, increased anteroposterior and mediolateral GRF on overweight subjects were observed. Conclusion: overweight individuals might adjust their gait characteristics in response to their increased weight to reduce overload lower limbs joints. These gait modifications pointed to a possible increase in the risk of musculoskeletal pathology in this population.
\end{abstract}

Keywords Gait analysis, Overweight, Principal component analysis, Walking.

\section{Introduction}

Obesity is a major global public health challenge. Excessive body weight is related to high incidence of chronic diseases such as cardiovascular disease, stroke, hypertension, diabetes and cancers of the large intestine, kidney, endometrium, and postmenopausal breast (Whitlock et al., 2009). In consequence, 2.8 million of deaths per year are associated to obesity (Darnton-Hill et al., 2004). In Brazil, according to the most recent survey (Brasil, 2017), the proportion of obese adults is $18.9 \%$ and overweight is $53.8 \%$.

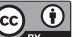

This is an Open Access article distributed under the terms of the Creative Commons Attribution License, which permits unrestricted use, distribution, and reproduction in any medium, provided the original work is properly cited.

How to cite this article: Silva FR, MunizAMS, Cerqueira LS, Nadal J. Biomechanical alterations of gait on overweight subjects. Res Biomed Eng. 2018; 34(4):291-298. DOI: 10.1590/2446-4740.180017

*Corresponding author: Programa de Engenharia Biomédica, Universidade Federal do Rio de Janeiro, Av. Horácio Macedo, 2030, Centro de Tecnologia, Bloco H, Sala 327, Cidade Universitária, CEP 21941-914, Rio de Janeiro, RJ, Brasil. E-mail: jn@peb.ufrj.br Received: 01 March 2018 / Accepted: 22 September 2018
Excessive body mass is associated to musculoskeletal conditions, osteoarthritis, low back pain, and soft tissue injury (McMillan et al., 2010; Imayama et al., 2011). The excess of body weight raises the forces acting on joint surfaces, increasing the difficulty to perform daily living activities (Imayama et al., 2011). As a result, mechanical stress due to obesity affects lower limbs and consequently change the gait pattern (McGraw et al., 2000). Spatiotemporal walking modifications comprise step length and walking speed reduction as well as increase of step width, double support, and stance times (McGraw et al., 2000; DeVita and Hortobagyi, 2003; Browning and Kram, 2007). Moreover, obese subjects walk with less knee and hip flexion and extension (McMillan et al., 2010), as well as increased ground reaction forces (GRF) (Browning and Kram, 2007).

Body mass index (BMI) is a standard measure of obesity level that is highly correlated to an individual's amount of body fat. This index is based on height and weight being applied to both men and women (Hall and Cole, 2006). For adults, such measure follows the standard convention (normal weight: 18.5 to $24.9 \mathrm{~kg} / \mathrm{m}^{2}$; overweight: 25 to $29.9 \mathrm{~kg} / \mathrm{m}^{2}$; and obese: $30 \mathrm{~kg} / \mathrm{m}^{2}$ or above) 
While obesity has been clinically associated with biomechanics changes in locomotion (Messier et al., 1994; Lai et al., 2008), gait of overweight subjects remains unreported. Therefore, there is a lack of studies on possible modifications in gait pattern of overweight subjects. The quantification of changes in the gait movements of overweight subjects is important to relate the possible risk of musculoskeletal injuries, by overloading the joints of the lower limbs.

The characterization of gait is performed by many signals which provide different information of highly correlated data (Astephen and Deluzio, 2005; Muniz and Nadal, 2009). Studies involving only a subjective selection of gait waveform parameters can be limited by loss of information (Muniz and Nadal, 2009). Thus, multivariate analysis methods such as principal component analysis (PCA) can be valuable and have been used to reduce the dimensionality of the data, analyzing the entire time series of the reference signal. This method transforms the original signal on a reduced set of uncorrelated data, retaining as much of the variance of the original signal as possible (Jolliffe, 2002).

The three-dimensional gait characteristics of overweight subjects are not clear. Therefore, the aim of this study is identifying biomechanics changes on gait in overweight subjects by applying PCA.

\section{Methods}

\section{Sample}

Two groups of mid-age adults volunteered for this study: overweight ( $\mathrm{n}=9$; three males; age of $49.6(6.2)$ years; mass of 79.7 (12.7) kg; height of $1.7(0.1) \mathrm{m}$ and body mass index (BMI) of $27.5(1.6) \mathrm{kg} / \mathrm{m}^{2}$ ) and normal-weight $(\mathrm{n}=15$; two males; age of 48.2 (6.4) years; height of $1.7(0.1) \mathrm{m}$; weight of $60.6(6.1) \mathrm{kg}$ and BMI of $\left.22.6(1.3) \mathrm{kg} / \mathrm{m}^{2}\right)$. BMI was used to classify the participants; overweight subjects (OG) had BMI values between 25.0 to $29.9 \mathrm{~kg} / \mathrm{m}^{2}$, and normal-weight subjects (CG) had BMI between 20.0 to $24.9 \mathrm{~kg} / \mathrm{m}^{2}$ (World..., 2015). All subjects signed a written informed consent approved by a local ethics committee, and were free of neurological illness, degenerative conditions or any general disease that might interfere on gait.

\section{Equipment and experimental procedures}

Three-dimensional kinematics of the lower limb and GRF were recorded with a synchronized Optotrak motion capture (Northern Digital, Ontario, Canada), and two force platforms (AMTI, Watertown, USA) system. Three-marker triads of infrared light-emitting diodes were placed on the pelvis, thigh, shank, and foot body segments. Individual markers on sacrum, the greater trochanter, the lateral epicondyle, the lateral malleolus, the posterior heel and the tip over the second metatarsal were identified during quiet standing and their positions were used together with four virtual markers to define anatomical coordinate systems (Landry et al., 2007). These measurements were obtained on the right side of the body. All signals were captured at $100 \mathrm{~Hz}$ sample frequency during $10 \mathrm{~s}$. The force platforms were mounted in series at the middle of a 10-meters walkway and covered with a gray carpet.

Each subject was required to walk barefoot on the walkway at his or her self-selected comfortable walking speed. Participants performed warm-up trials prior to data collection to establish a starting point so that each foot hit one of the force platforms during walking trials. Data collection continued until the subject completed at least five successful trials.

\section{Signal processing}

For each subject, kinematic and GRF data were filtered using low pass Butterworth filters with cut-off frequency $7 \mathrm{~Hz}$ and $30 \mathrm{~Hz}$, respectively; moreover, GRF data were normalized by each subject body weight.

For time normalization, each kinematic and GRF waveform was interpolated using cubic spline and resampled with 51 points which corresponded to $2 \%$ resolution in the complete gait cycle for kinematic data and stance phase for GRF data. The posterior heel and the tip over the second metatarsal markers were used to determine foot contact events according to algorithm developed by O'Connor et al. (2007). Although temporal differences between gait cycle events still may exist (Helwig et al., 2011), such normalization method is the most used in PCA application of gait studies (Astephen and Deluzio, 2005; Muniz and Nadal, 2009; Muniz et al., 2010)

Afterwards, averaged data from five trials were obtained for each gait signal. Gait velocity was calculated using pelvic marker, as well as stride length and cadence using calcaneus marker. Joint angular position was calculated for hip, knee, and ankle joints which were afterwards evaluated using PCA. Sagittal, frontal and transverse kinematic waveform data from each joint, as well as vertical, anteroposterior and mediolateral GRF component were separately stored in a matrix $\mathbf{E}$ with 24 rows (corresponding to $\mathrm{CG}$ and $\mathrm{OG}$ ) and 51 columns (samples of each gait waveform). PCA was applied to the covariance matrix $\mathbf{S}(51 \times 51)$ obtained from each E, by the solutions of the linear system (Jolliffe, 2002).

$$
S x_{p}=\lambda_{p} x_{p}
$$

where $\lambda$ is the eigenvalue of $\mathbf{S}$ ranked in decreasing order and $\mathbf{x}$ is the corresponding normalized eigenvector or principal component (PC). Each PC is an uncorrelated waveform obtained from linear combination of the 
original data vectors. The first PCs correspond to signals with larger variances, being orthogonal to each other. The scree test (Jolliffe, 2002) selected the relevant PCs for the analysis. The orthogonal projection of an original observation onto a PC was referred to as principal component score (PC scores) (Jolliffe, 2002) and the group differences were assessed by comparing the PC scores obtained for the relevant PCs. Each eigenvector presents the same number of points of the original waveform data (51), where each point represents the loading factor applied to corresponding sample of the original waveform (McKean et al., 2007). Therefore, to help the interpretation of the attained information by those PCs which presented statistical difference between groups, the averaged waveforms of overweight subjects were qualitatively compared between groups (Muniz et al., 2010).

\section{Statistical analysis}

The normality of the datasets containing gait velocity and PC scores was tested by the Kolmogorov-Smirnov test which presented non-normal distribution. Therefore, the Mann Whitney test was applied to compare PC scores between groups. The significance level was set to $\alpha=0.05$. All signal processing procedures and statistical tests were performed using Matlab version 7.1 (The Mathworks, USA).

\section{Results}

There was no significant difference in gait velocity $(\mathrm{CG}=4.4 \pm 0.4 ; \mathrm{OG}=4.3 \pm 0.4 \mathrm{~km} / \mathrm{h} ; p=0.52)$, stride length $(\mathrm{CG}=1.15 \pm 0.06 ; \mathrm{OG}=1.24 \pm 0.14 \mathrm{~m} ; p=0.20)$ and cadence $(C G=73.5 \pm 19.6 ; O G=73.5 \pm 9.6$ strides $/ \mathrm{min}$; $p=0.08$ ) between groups, thus avoiding any group differences in gait characteristics directly due to gait speed.

All PC scores are summarized in Table 1. The scree test indicated that three PCs from sagittal, frontal and transverse planes should be considered in the ankle joint analysis, which retained respectively $91.0 \%, 87.5 \%$ and $90.7 \%$ of the total data variance. However, only the first PC score from the sagittal plane presented a statistical difference between groups (Table 1). This PC presented the highest loading factors (values far from zero) during pre-swing phase (Figure 1) where signal epochs presented a marked difference between group averages. Such result pointed to a reduced ankle plantarflexion at toe-off in overweight subjects. PC scores from frontal and transverse range of motion at the ankle presented no statistical difference between the groups (Table 1), indicating that there is no difference between $\mathrm{OG}$ and $\mathrm{CG}$ in these planes of motion.

Three PCs in the sagittal, frontal and transverse planes at the knee should be considered in the analysis,
Table 1. PC scores from control group (CG) and overweight group (OG) and respective $p$ values. Data are presented by mean (standard deviation)

\begin{tabular}{|c|c|c|c|c|c|}
\hline & & & CG & OG & $p$ \\
\hline \multirow{9}{*}{$\begin{array}{l}\mathbf{A} \\
\mathbf{N} \\
\mathbf{K} \\
\mathbf{L} \\
\mathbf{E}\end{array}$} & \multirow{3}{*}{ Sagittal } & PC1 & $5.3(4.4)$ & $-0.9(17.7)$ & $0.026^{*}$ \\
\hline & & $\mathrm{PC} 2$ & $2.3(10.9)$ & $-4.3(5.5)$ & 0.146 \\
\hline & & PC3 & $-0.3(8.1)$ & $0.5(9.1)$ & 0.638 \\
\hline & \multirow{3}{*}{ Frontal } & PC1 & $-0.2(25.6)$ & $9.7(16.9)$ & 0.165 \\
\hline & & $\mathrm{PC} 2$ & $2.8(10.2)$ & $-0.2(10.6)$ & 0.165 \\
\hline & & $\mathrm{PC} 3$ & $-0.9(8.6)$ & $1.8(5.9)$ & 0.420 \\
\hline & \multirow{3}{*}{ Transverse } & $\mathrm{PC} 1$ & $-0.1(32.2)$ & $9.5(18.6)$ & 0.383 \\
\hline & & $\mathrm{PC} 2$ & $0.4(11.7)$ & $-0.7(14.7)$ & 0.723 \\
\hline & & PC3 & $1.6(8.9)$ & $-3.0(5.0)$ & 0.129 \\
\hline \multirow{9}{*}{$\begin{array}{l}\mathbf{K} \\
\mathbf{N} \\
\mathbf{E} \\
\mathbf{E}\end{array}$} & \multirow{3}{*}{ Sagittal } & PC1 & $6.3(28.2)$ & $-11.8(37.9)$ & 0.287 \\
\hline & & $\mathrm{PC} 2$ & $3.4(15.8)$ & $-6.4(18.1)$ & 0.146 \\
\hline & & $\mathrm{PC} 3$ & $1.9(11.4)$ & $-3.6(14.4)$ & 0.383 \\
\hline & \multirow{3}{*}{ Frontal } & $\mathrm{PC} 1$ & $6.2(49.7)$ & $-11.7(36.9)$ & 0.430 \\
\hline & & $\mathrm{PC} 2$ & $-0.6(7.3)$ & $1.2(11.1)$ & 0.628 \\
\hline & & PC3 & $-0.3(4.2)$ & $0.6(10.7)$ & 0.923 \\
\hline & \multirow{3}{*}{ Transverse } & $\mathrm{PC} 1$ & $1.6(53.8)$ & $-2.9(61.6)$ & 1.000 \\
\hline & & PC2 & $0.3(16.2)$ & $-0.6(15.0)$ & 1.000 \\
\hline & & PC3 & $-1.9(12.4)$ & $3.6(17.0)$ & 0.349 \\
\hline \multirow{9}{*}{$\begin{array}{c}\mathbf{H} \\
\mathbf{I} \\
\mathbf{P}\end{array}$} & \multirow{3}{*}{ Sagittal } & $\mathrm{PC} 1$ & $-0.9(30.5)$ & $1.6(26.6)$ & 0.974 \\
\hline & & $\mathrm{PC} 2$ & $0.8(11.1)$ & $-1.5(18.3)$ & 0.583 \\
\hline & & PC3 & $4.3(7.4)$ & $-8.1(11.2)$ & $0.015^{*}$ \\
\hline & \multirow{3}{*}{ Frontal } & $\mathrm{PC} 1$ & $-2.3(21.0)$ & $4.4(21.2)$ & 0.259 \\
\hline & & $\mathrm{PC} 2$ & $-1.1(13.2)$ & $2.0(14.1)$ & 0.498 \\
\hline & & $\mathrm{PC} 3$ & $-0.1(9.9)$ & $0.3(14.1)$ & 0.821 \\
\hline & \multirow{3}{*}{ Transverse } & PC1 & $-0.1(29.2)$ & $0.14(24.1)$ & 1.000 \\
\hline & & PC2 & $0.9(8.9)$ & $-1.63(14.1)$ & 0.349 \\
\hline & & $\mathrm{PC} 3$ & $-1.0(9.1)$ & $9.14(9.3)$ & 0.723 \\
\hline \multirow{10}{*}{$\begin{array}{l}\mathbf{G} \\
\mathbf{F} \\
\mathbf{R}\end{array}$} & \multirow{4}{*}{ Vertical } & $\mathrm{PC} 1$ & $-0.5(0.3)$ & $0.1(0.3)$ & 0.420 \\
\hline & & $\mathrm{PC} 2$ & $0.1(0.2)$ & $-0.1(0.3)$ & 0.420 \\
\hline & & PC3 & $-0.0(0.2)$ & $0.0(0.1)$ & 0.771 \\
\hline & & PC4 & $-0.0(0.1)$ & $0.0(0.2)$ & 0.208 \\
\hline & \multirow{3}{*}{ Anteroposterior } & $\mathrm{PC} 1$ & $0.0(0.1)$ & $-0.1(0.1)$ & $0.031 *$ \\
\hline & & $\mathrm{PC} 2$ & $0.0(0.1)$ & $-0.0(0.1)$ & 0.974 \\
\hline & & $\mathrm{PC} 3$ & $-0.0(0.0)$ & $0.0(0.0)$ & 1.000 \\
\hline & \multirow{3}{*}{ Mediolateral } & $\mathrm{PC} 1$ & $-0.0(0.1)$ & $0.1(0.1)$ & $0.042 *$ \\
\hline & & $\mathrm{PC} 2$ & $0.0(0.1)$ & $-0.0(0.1)$ & 1.000 \\
\hline & & $\mathrm{PC} 3$ & $0.0(0.0)$ & $-0.0(0.0)$ & $0.042 *$ \\
\hline
\end{tabular}

*Statistical difference between groups.

retaining respectively $91.4 \%, 97.6 \%$ and $94.6 \%$ of the total data variance. Nevertheless, any comparison of these PCs scores presented statistical difference between groups (Table 1).

The hip joint presented three PCs in the sagittal, frontal and transverse planes retained in the analysis, with respectively $94.0 \%, 88.7 \%$ and $89.2 \%$ of the total data variance. However, only the third PC score from the sagittal plane presented statistical difference between groups (Table 1). Higher loading factors were observed at the initial contact, terminal stance and mid swing (Figure 2). Overweight subjects presented lower 
averaged signal amplitude at these gait phases. Such results pointed to a reduced hip flexion at the heel strike and at mid swing gait phases, as well as a reduced hip extension during push off. Frontal and transverse hip range of motion showed no statistical difference between groups in PC scores (Table 1).

GRF analysis resulted in four PCs from the vertical axis and three PCs from both anteroposterior and mediolateral axes, retaining respectively $81.6 \%, 79.0 \%$ and $85.8 \%$
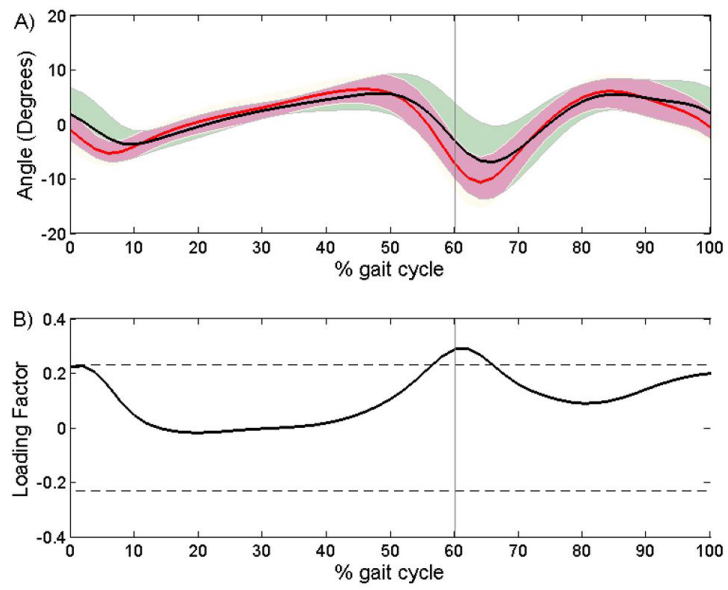

Figure 1. (A) Averaged sagittal ankle motion from control group (red line) and overweight group (black line) with its respective shaded standard deviations. (B) The first principal component (continuous line) and dotted lines representing the threshold of $80 \%$ of the maximum loading factor. The vertical line represents gait cycle division between stance (from 0 to $60 \%$ ) and swing (from 60 to $100 \%$ ).
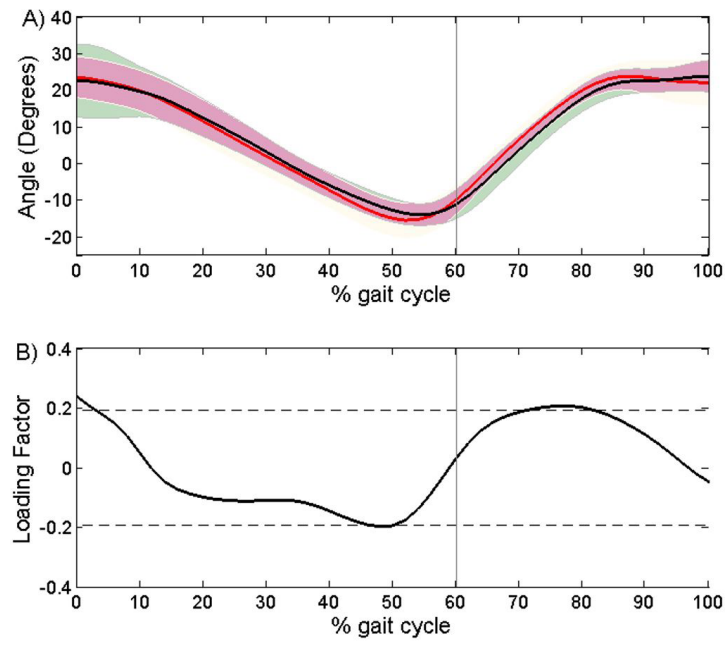

Figure 2. (A) Averaged sagittal hip motion from control group (red line) and overweight group (black line) with its respective shaded standard deviations. (B) The third principal component (continuous line) and dotted lines representing the threshold of $80 \%$ of the maximum loading factor. The vertical line represents gait cycle division between stance (from 0 to $60 \%$ ) and swing (from 60 to $100 \%$ ). of the data variance. While vertical GRF component presented no statistical difference between groups, the first PC score from anteroposterior and the first and third from mediolateral axes were statistically different (Table 1). In the anteroposterior direction, higher loading factors were observed at the initial contact (Figure 3), with increased GRF amplitude in OG on this stance phase of gait. Additionally, mediolateral GRF component presented higher loading factor at loading response phase for both first and third PCs (Figure 4), at mid-stance (third PC) and at push off (first PC) (Figure 4B). Overweight subjects presented increased averaged mediolateral GRF amplitude in all these epochs.

\section{Discussion}

The purpose of the study was to examine the effects of overweight on gait characteristics. PCA was used for analyzing the entire signals waveforms instead of using only discrete parameters that do not consider the high degree of correlation that exists between various aspects of an individual's gait (Tingley et al., 2002). Overweight subjects walked with significant kinematic motion modification in the sagittal plane at ankle and hip joints and showed significant changes in anteroposterior and mediolateral GRF.

Overweight subjects did not change gait speed, stride length and cadence compared to controls, while obese subjects are associated with slow gait speed (DeVita and Hortobagyi, 2003; Browning and Kram, 2007). Such change is related to a strategy of obese subjects in reduce the knee-joint load (DeVita and Hortobagyi, 2003). Gait speed is frequently used for evaluation of disability in clinical intervention trials and daily settings
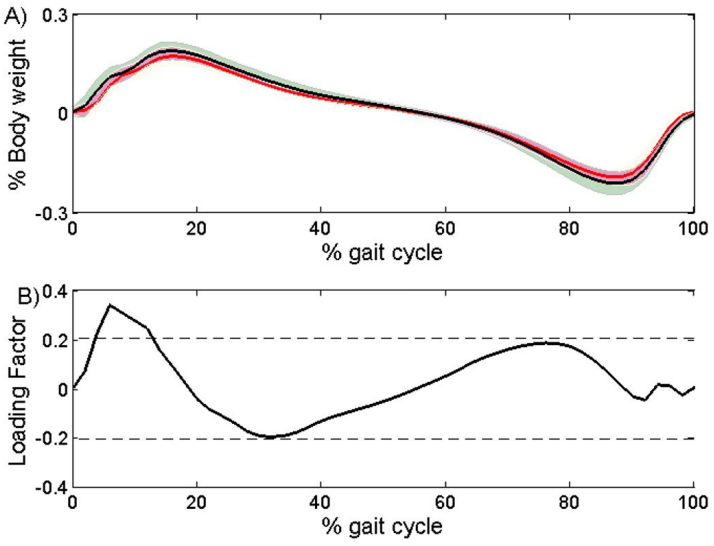

Figure 3. (A) Averaged anteroposterior ground reaction force from control group (red line) and overweight group (black line) with its respective shaded standard deviations. (B) The first principal component (continuous line) and dotted lines representing the threshold of $80 \%$ of the maximum loading factor. 
A)

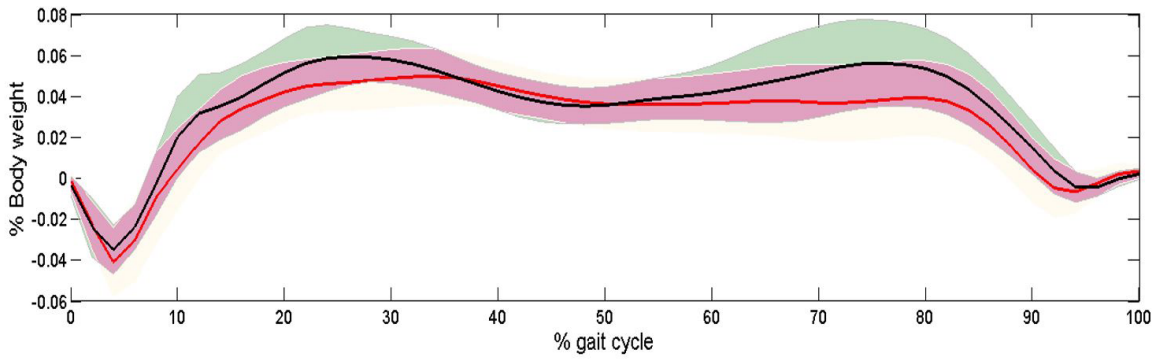

B)

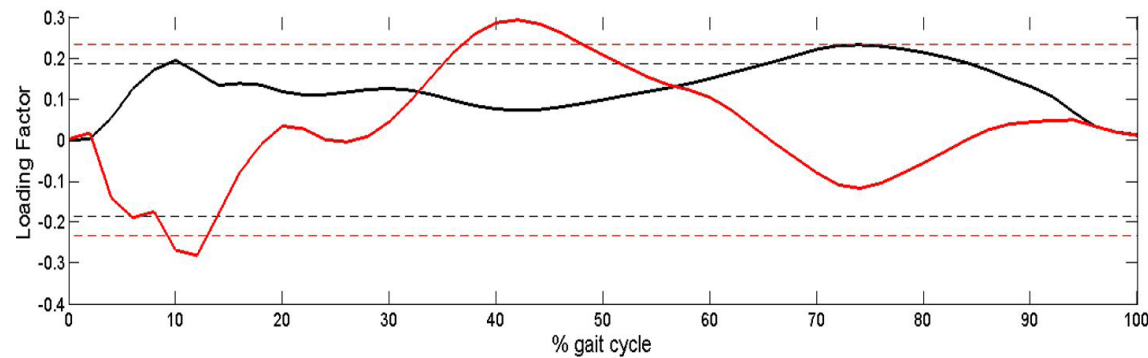

Figure 4. (A) Averaged mediolateral ground reaction force from control group (red line) and overweight group (black line) with its respective shaded standard deviations. (B) The first principal component (black line) and the third principal component (red line), dotted lines representing the threshold of $80 \%$ of the maximum loading factor.

(Cesari et al., 2005). Therefore, walking at similar speed suggest similar functional mobility between groups.

PCA pointed to sagittal ankle kinematic modification with visual plantarflexion reduction at toe-off in $\mathrm{OG}$ (Figure 1). Reports of kinematic and kinetic characteristics of walking in individuals who are obese are inconsistent. Spyropoulos et al. (1991) also found lower peak of plantarflexion in adults and adolescent who are obese, associating decreased range of motion at toe-off to a possible weakness of plantiflexor muscles and to a mechanical action of the accumulation of adipose tissue at the ankle joint region. However, DeVita and Hortobagyi (DeVita and Hortobagyi, 2003) found a higher plantarflexion angle at toe-off in obese subjects, attributing these results to a decreased knee torque. Lai et al. (2008) investigated the three-dimensional gait characteristics of Chinese obese adults, founding no significant difference between obese and normal weight subjects in the sagittal plane motion. McMillan et al. (2010) also found no difference in peak plantarflexion; however, these authors observed a reduced plantarflexion moment at late stance in obese subjects that might be due to relative plantiflexor muscles weakness, as these muscles are partial contributors to ankle joint moments in the sagittal plane. Although none of these studies analyzed overweight subjects, and the present study did not analyze electromyography data, the reduced plantar flexion at push-off suggest a possible weakness of plantiflexor muscles in overweight subjects that should be further investigated.
Ankle joint did not present differences between groups in the frontal and transverse planes of motion. Similar result was found by McMillan et al. (2010) in obese subjects attributing this result to the inclusion of female samples, since they found reduced eversion motion peak amplitude in obese boys. Conversely, Lai et al. (2008) found increased ankle eversion at mid and terminal stance, as well as at pre-swing in male and female in obese subjects. Although further investigations of differences in mechanics between males and females who are overweight are required, the present results pointed to that overweight could not be enough to cause changes in the ankle movement during gait of motions in the frontal and transverse planes.

Overweight has been clinically associated with musculoskeletal disorder of back, hip, knee, ankle and foot (Messier et al., 2005). Changes in the knee joint during walking in obese individuals have been intensively reported in the literature, with reduced knee flexion amplitude due to possible weakness of the knee extensors (Gushue et al., 2005; Landry et al., 2007; McMillan et al., 2010), as well as an increase in knee abduction that in the long term which may lead to osteoarthritis (Baliunas et al., 2002; Gushue et al., 2005). However, the present results differ from these findings, since there was no significant difference in knee motion PC scores during gait in the overweight group compared to those with normal weight (Table 1). Such outcome suggests that overweight subjects reorganize their neuromuscular function during walking, to reduce ankle plantarflexion 
and hip extension during push-off, but they are able to maintain the same knee motion pattern observed in control subjects. DeVita and Hortobagyi (2003) found less knee torque and power in obese individuals while walking at a self-selected speed and equal knee torque and power while walking at the same speed as control subjects. According to these authors, the reduced gait speed in obese shows the ability of these individuals to reduce the total load on the knee joint. Since the studied OG presented no difference in gait speed compared to $\mathrm{CG}$, they could reduce repetitive stresses without change knee kinematic patterns as reported in obese people. Foti et al. (2000) reported knee kinematic motion during gait remained unchanged in women at late pregnancy while carrying $13 \mathrm{~kg}$ more mass compared after one-year post-partum. These authors suggest increased demands on hip abductor, hip extensor, and ankle plantar flexor muscles during walking to compensate for additional body weight and reduce knee loads.

Overweight subjects presented changes in hip movement in the sagittal plane. Visual comparison between groups pointed to reduced hip flexion at the heel strike and at mid swing gait phases, as well as a reduced hip extension during push off (Figure 2B). Reduced hip movement was also found for adults (DeVita and Hortobagyi, 2003) and adolescents (McMillan et al., 2010) obese populations. On contrary, Lai et al. (2008) found no significant difference between obese and normal weight subjects in the sagittal hip kinematic data. McMillan et al. (2010) suggested that the reduced hip flexion is linked to a strategy to compensate for a possible weakness of the hip extensor muscles. Blocking plantarflexion movement in normal subjects, Romkes and Schweizer (2015) observed lower extension at the hip joint during push off and suggested this change as a response to a decreased function of plantiflexor muscles during the push-off phase. Therefore, muscle weakness could explain the reduced plantarflexion and hip extension during push off observed in overweight subjects. Additionally, the reduced hip movement in the sagittal plane could be associated with a gait strategy to overweight subjects maintain up-righted postural stability. According to Colné et al. (2008), the increased body weight can cause postural instability.

On the other hand, it was not observed difference between groups in the frontal and transverse hip movements. Similarly, Lai et al. (2008) did not find hip rotation differences in obese subjects. However, these authors found lower hip abduction moment during early stance. The authors related this change to the relative hip abductor weakness, as a strategy used to maintain vertical stability during the transitional phase of stance for the swing. Therefore, these results point to adequate vertical stability during gait, resulting from a possible adequate abductor force in overweight subjects.

Vertical GRF shows no difference between groups. This result could be explained by the similar speed during walking between groups. Some authors (Messier et al., 1996; Browning and Kram, 2007) state that the increase of the vertical GRF peak is proportional to body mass. Thus, it suggests that overweight is not enough to cause significant change in vertical force. Waveform analysis evidenced higher anteroposterior GRF at braking force in overweight subjects. Most of the studies suggests an increase in anteroposterior GRF proportional to the applied load carriage (Kinoshita, 1985; Birrell et al., 2007). Conversely, in obese subjects Lai et al. (2008) found reduced braking and propulsive forces associated with lower gait speed. In the present study, as both groups walked in similar speed, the increase braking force can be associate with increased body mass in overweight subjects. Additionally, mediolateral GRF component pointed to higher values during initial contact and push off (Figure 4). Browning and Kram (2007) also observed higher mediolateral GRF in obese subjects and associated to a possible gait instability in this population. The limitation of this study was the small sample size and lack of power and moment joint calculation.

As a conclusion, the overweight subjects walked with kinematic motion modification in the sagittal plane at ankle and hip joints, including: reduced hip flexion during heel strike, reduced plantarflexion and hip extension during toe-off, as well as reduced hip flexion during mid-swing. Changes were also observed in anteroposterior and mediolateral GRF, in which overweight subjects presented higher braking force and mediolateral GRF compared to the control group. This result supports that overweight subjects adjust their gait characteristics in response to their increased weight which could increase risk of musculoskeletal pathology.

\section{Acknowledgements}

This work was supported by the Brazilian agencies CNPq and CAPES.

\section{References}

Astephen JLK, Deluzio J. Changes in frontal plane dynamics and the loading response phase of the gait cycle are characteristic of severe knee osteoarthritis application of a multidimensional analysis technique. Clin Biomech. 2005; 20(2):209-17. http:// dx.doi.org/10.1016/j.clinbiomech.2004.09.007. PMid:15621327.

Baliunas AJD, Hurwitz E, Ryals AB, Karrar A, Case JP, Block JA, Andriacchi TP. Increased knee joint loads during walking are present in subjects with knee osteoarthritis. Osteoarthritis Cartilage. 2002; 10(7):573-9. http://dx.doi.org/10.1053/ joca.2002.0797. PMid:12127838. 
Birrell SA, Hooper RH, Haslam RA. The effect of military load carriage on ground reaction forces. Gait Posture. 2007; 26(4):611-4. http://dx.doi.org/10.1016/j.gaitpost.2006.12.008. PMid:17337189.

Brasil. Ministério da Saúde. Secretaria de Vigilância em Saúde. Departamento de Vigilância de Doenças e Agravos não Transmissíveis e Promoção da Saúde. Vigitel Brasil 2016: vigilância de fatores de risco e proteção para doenças crônicas por inquérito telefônico [internet]. Brasília: Ministério da Saúde; 2017. 160 p. [cited 2018 Dez 09]. Available from: http://portalarquivos2.saude.gov.br/images/pdf/2018/marco/02/ vigitel-brasil-2016.pdf.

Browning RC, Kram R. Effects of obesity on the biomechanics of walking at different speeds. Med Sci Sports Exerc. 2007; 39(9):1632-41. PMid:17805097.

Cesari M, Kritchevsky SB, Penninx BWHJ, Nicklas BJ, Simonsick EM, Newman AB, Tylavsky FA, Brach JS, Satterfield S, Bauer DC, Visser M, Rubin SM, Harris TB, Pahor M. Prognostic value of usual gait speed in well-functioning older people - results from the Health, Aging and Body Composition Study. J Am Geriatr Soc. 2005; 53(10):1675-80. http://dx.doi. org/10.1111/j.1532-5415.2005.53501.x. PMid:16181165.

Colné P, Frelut ML, Peres G, Thoumie P. Postural control in obese adolescents assessed by limits of stability and gait initiation. Gait Posture. 2008; 28(1):164-69. http://dx.doi. org/10.1016/j.gaitpost.2007.11.006. PMid:18191568.

Darnton-Hill I, Nishida C, James WP. Alife course approach to diet, nutrition and the prevention of chronic diseases. Public Health Nutr. 2004; 7(1A):101-21. http://dx.doi.org/10.1079/ PHN2003584. PMid:14972056.

DeVita P, Hortobagyi T. Obesity is not associated with increased knee joint torque and power during level walking. J Biomech. 2003; 36(9):1355-62. http://dx.doi.org/10.1016/ S0021-9290(03)00119-2. PMid:12893044.

Foti T, Davids JR, Bagley A. A biomechanical analysis of gait during pregnancy. J Bone Joint Surg Am. 2000; 82(5):62532. http://dx.doi.org/10.2106/00004623-200005000-00003. PMid:10819273.

Gushue DL, Houck J, Lerner AL. Effects of childhood obesity on three-dimensional knee joint biomechanics during walking. J Pediatr Orthop. 2005; 25(6):763-68. http://dx.doi. org/10.1097/01.bpo.0000176163.17098.f4. PMid:16294133.

Hall DMB, Cole TJ. What use is the BMI. Arch Dis Child. 2006; 91(4):283-6. http://dx.doi.org/10.1136/adc.2005.077339. PMid:16551784.

Helwig NE, Hong S, Hsiao-Wecksler ET, Polk JD. Methods to temporally align gait cycle data. J Biomech. 2011; 44(3):561-6. http://dx.doi.org/10.1016/j.jbiomech.2010.09.015. PMid:20887992.

Imayama I, Alfano CM, Kong A, Foster-Schubert KE, Bain CE, Xiao L, Duggan C, Wang CY, Campbell KL, Blackburn GL, McTiernan A. Dietary weight loss and exercise interventions effects on quality of life in overweight/obese postmenopausal women: a randomized controlled trial. Int J Behav Nutr Phys Act. 2011; 8(1):118. http://dx.doi.org/10.1186/1479-5868-8118. PMid:22026966.

Jolliffe IT. Principal component analysis. 2nd ed. New York: Springer; 2002.
Kinoshita H. Effects of different loads and carrying systems on selected biomechanical parameters describing walking gait. Ergonomics. 1985; 28(9):1347-62. http://dx.doi. org/10.1080/00140138508963251. PMid:4065090.

Lai PPK, Leung AK, Li AN, Zhang M. Three-dimensional gait analysis of obese adults. Clin Biomech. 2008; 23:(4 Suppl 1):S2-6.

McGraw B, McClenaghan BA, Williams HG, Dickerson J, Ward DS. Gait and postural stability in obese and non obese prepubertal boys. Arch Phys Med Rehabil. 2000; 81(4):4849. http://dx.doi.org/10.1053/mr.2000.3782. PMid:10768540.

McKean KA, Landry SC, Hubley-Kozey CL, Dunbar MJ, Stanish WD, Deluzio KJ. Gender differences exist in osteoarthritic gait. Clin Biomech (Bristol, Avon). 2007; 22(4):400-9. http://dx.doi. org/10.1016/j.clinbiomech.2006.11.006. PMid:17239509.

McMillan AG, Pulver AME, Collier DN, Williams DSB. Sagittal and frontal plane joint mechanics throughout the stance phase of walking in adolescents who are obese. Gait Posture. 2010; 32(2):263-8. http://dx.doi.org/10.1016/j.gaitpost.2010.05.008. PMid:20573511.

Messier SP, Davies AB, Moore DT, Davis SE, Pack RJ, Kazmar SC. Severe obesity: Effects on foot mechanics during walking. Foot Ankle Int. 1994; 15(1):29-34. http://dx.doi. org/10.1177/107110079401500106. PMid:7981793.

Messier SP, Ettinger WH Jr, Doyle TE, Morgan T, James M, O'Toole M, Burns R. Obesity: Effects on gait in an osteoarthritic population. J Appl Biomech. 1996; 12(2):161-72. http://dx.doi. org/10.1123/jab.12.2.161.

Messier SP, Gutekunst DJ, Davis C, DeVita P. Weight loss reduces knee-joint loads in overweight and obese older adults with knee osteoarthritis. Arthritis Rheum. 2005; 52(7):2026-32. http://dx.doi.org/10.1002/art.21139. PMid:15986358.

Muniz AMS, Liu H, Lyons KE, Pahwa R, Liu W, Nadal J. Quantitative evaluation of the effects of subthalamic stimulation on gait in Parkinson's Disease patients using Principal Component Analysis. Int J Neurosci. 2010; 120(9):609-16. http://dx.doi.or g/10.3109/00207454.2010.504904. PMid:20707636.

Muniz AMS, Nadal J. Application of principal component analysis in vertical ground reaction force to discriminate normal and abnormal gait. Gait Posture. 2009; 29(1):31-5. http:// dx.doi.org/10.1016/j.gaitpost.2008.05.015. PMid:18640040.

Romkes J, Schweizer K. Immediate effects of unilateral restricted ankle motion on gait kinematics in healthy subjects. Gait Posture. 2015; 41(3):835-40. http://dx.doi.org/10.1016/j. gaitpost.2015.02.015. PMid:25800648.

Spyropoulos P, Pisciotta JC, Pavlou KN, Cairns MA, Simon SR. Biomechanics gait analysis in obese men. Arch Phys Med Rehabil. 1991; 72(13):1065-70. PMid:1741658.

Tingley M, Wilson C, Biden E, Knight WR. An index to quantify normality of gait in young children. Gait Posture. 2002; 16(2):149-58. http://dx.doi.org/10.1016/S0966-6362(02)000127. PMid:12297256.

World Health Organization. What are overweight and obesity? [internet]. Geneva: WHO; 2015. [cited 2016 Out 5]. Avaliable from: http://www.who.int/mediacentre/factsheets/fs311/en/ 
O'Connor CM, Thorpe SK, O'Malley MJ, Vaughan CL. Automatic detection of gait events using kinematic data. Gait Posture. 2007; 25(3):469-74. http://dx.doi.org/10.1016/j. gaitpost.2006.05.016. PMid:16876414.

Landry SC, McKean KA, Hubley-Kozey CL, Stanish WD, Deluzio KJ. Knee biomechanics of moderate OA patients measured during gait at a self-selected and fast walking speed.
J Biomech. 2007; 40(8):1754-61. http://dx.doi.org/10.1016/j. jbiomech.2006.08.010. PMid:17084845.

Whitlock G, Lewington S, Sherliker P, Clarke R, Emberson J, Halsey J, Qizilbash N, Collins R, Peto R. Prospective Studies Collaboration: Body-mass index and cause-specific mortality in 900000 adults: collaborative analyses of 57 prospective studies. Lancet. 2009; 373(9669):1083-96. 